\title{
High-speed video observations of rocket-and-wire initiated lightning
}

\author{
C. J. Biagi, ${ }^{1}$ D. M. Jordan, ${ }^{1}$ M. A. Uman, ${ }^{1}$ J. D. Hill, ${ }^{1}$ W. H. Beasley, ${ }^{2}$ and J. Howard ${ }^{1}$ \\ Received 4 April 2009; revised 31 May 2009; accepted 11 June 2009; published 1 August 2009.
}

[1] We present observations of a rocket-and-wire triggered lightning flash obtained with high-speed video cameras recording 5400 and 50000 frames per second (frame times $185 \mu \mathrm{s}$ and $20 \mu \mathrm{s}$ ) with time-synchronized current and electric field measurements. Transient leader channels were observed with precursor current pulses occurring before the development of the sustained upward positive leader that initiated the initial continuous current. The sustained upward positive leader stepped with a constant speed of $5.6 \times 10^{4} \mathrm{~m} \mathrm{~s}^{-1}$ over its initial $100 \mathrm{~m}$. The wire destruction occurred discontinuously over a time of $7 \mathrm{~ms}$ about $45 \mathrm{~ms}$ after sustained upward leader inception, with a small change in channel current. Downward leaders, upward connecting leaders, and filamentary streamers were imaged in the bottom $50 \mathrm{~m}$ of the channel. We present the first images of a negative step forming in lightning, apparently involving a space stem similar to steps in meter-length negative laboratory sparks. Citation: Biagi, C. J., D. M. Jordan, M. A. Uman, J. D. Hill, W. H. Beasley, and J. Howard (2009), Highspeed video observations of rocket-and-wire initiated lightning, Geophys. Res. Lett., 36, L15801, doi:10.1029/2009GL038525.

\section{Introduction}

[2] Streak photography on film has been the most common method of obtaining time and space resolved optical measurements, both for rocket-and-wire triggered and natural lightning [e.g., Schonland, 1956; Berger and Vogelsanger, 1966; Orville and Idone, 1982; Jordan et al., 1992; Olsen et al., 2006]. The use of photodiode arrays has offered an alternate method of obtaining high-speed optical measurements [e.g., Yokoyama et al., 1990; Wang et al., 1999a, 1999b, 1999c; Olsen et al., 2004; Lu et al., 2008], generally exhibiting an order of magnitude faster timeresolution than streak photography, but with poorer spatial resolution and more ambiguity in the data interpretation. High-speed digital video photography is a relatively new technology that provides optical data with both relatively high time and spatial resolution [e.g., Ballarotti et al., 2005; Qie and Kong, 2007; Saba et al., 2008]. Using high-speed video observations of a triggered nine-stroke flash at frame times of $20 \mu \mathrm{s}$ and $185 \mu \mathrm{s}$ with time-synchronized current and electric field measurements, we present the first published observations of luminous leader channels associated with precursor current pulse bursts occurring before the initiation of an upward positive leader (UPL), a unique view of the destruction of the triggering wire, the first images of

\footnotetext{
${ }^{1}$ Department of Electrical and Computer Engineering, University of Florida, Gainesville, Florida, USA.

${ }^{2}$ School of Meteorology, University of Oklahoma, Norman, Oklahoma, USA.
}

Copyright 2009 by the American Geophysical Union. 0094-8276/09/2009GL038525\$05.00 upward connecting and downward leaders prior to connection, the first well-resolved images of leader-step formation, and general data of interest on the flash.

\section{Experiment}

[3] The measurements presented were made at the International Center for Lightning Research and Testing (ICLRT) in north-central Florida. The flash was triggered on 17 September 2008 at 22:04:15 (GMT) by a rocket trailing an unspooling Kevlar-covered $0.2 \mathrm{~mm}$ diameter copper wire. The wire was connected to ground but had several centimeter-size gaps present just above ground for purposes of a separate experiment. At rocket launch the ground-level electric field was $-6.2 \mathrm{kV} \mathrm{m}^{-1}$ (atmospheric electricity sign convention).

[4] The initial continuous current (ICC) of the flash was physically separated from the nine return stroke (RS) currents by intercepting the leaders preceding the return strokes with a $4 \mathrm{~m}$ square horizontal wire located $17 \mathrm{~m}$ above ground level (AGL) and centered over the rocket launcher. The launch tubes are $3 \mathrm{~m}$ tall (14 m AGL) and rest atop an $11 \mathrm{~m}$ launch tower. Measurements presented here include current in both paths (ICC and RS) to ground, measured with Pearson current transformers with a $3 \mathrm{~dB}$ bandwidth of $10 \mathrm{~Hz}$ to $3 \mathrm{MHz}$, and electric field measured with a wideband capacitive flat-plate antenna with a $3 \mathrm{~dB}$ bandwidth of $16 \mathrm{~Hz}$ to $3 \mathrm{MHz}$ that was located $360 \mathrm{~m}$ from the launch tower. The ICC-path current data were mathematically processed to compensate for the low frequency response. The data were recorded with 12-bit resolution and sample rates of $5 \mathrm{MHz}$ and $10 \mathrm{MHz}$.

[5] High-speed video data were acquired using two Photron FASTCAM SA1.1 cameras. Camera 1 was operated at 5400 frames-per-second (fps) $(185.2 \mu$ s per frame $)$ using its full spatial resolution of $1024 \times 1024$ pixels. Camera 2 was operated at $50,000 \mathrm{fps}(20 \mu \mathrm{s}$ per frame $)$ with a reduced spatial resolution of $320 \times 128$ pixels. There was no dead time between frames. Image data presented here from both cameras have been cropped and contrast-enhanced to show the salient features of the lightning flash more clearly. Both cameras recorded in 12-bit gray scale and were synchronized to GPS timing. Lightning channel lengths and heights were estimated from the pixel size $\left(20 \mu \mathrm{m}^{2}\right)$ and lens focal lengths of $24 \mathrm{~mm}$ and $54 \mathrm{~mm}$. The two cameras were co-located $440 \mathrm{~m}$ from the launch tower.

\section{Results and Discussion}

\subsection{Attempted Upward Leaders}

[6] In rocket-and-wire triggered lightning, dampedoscillatory current pulses (precursors) typically occur prior to the inception of the sustained UPL [e.g., Lalande et al., 1998; Willett et al., 1999]. Figure 1 shows the ICC-path 


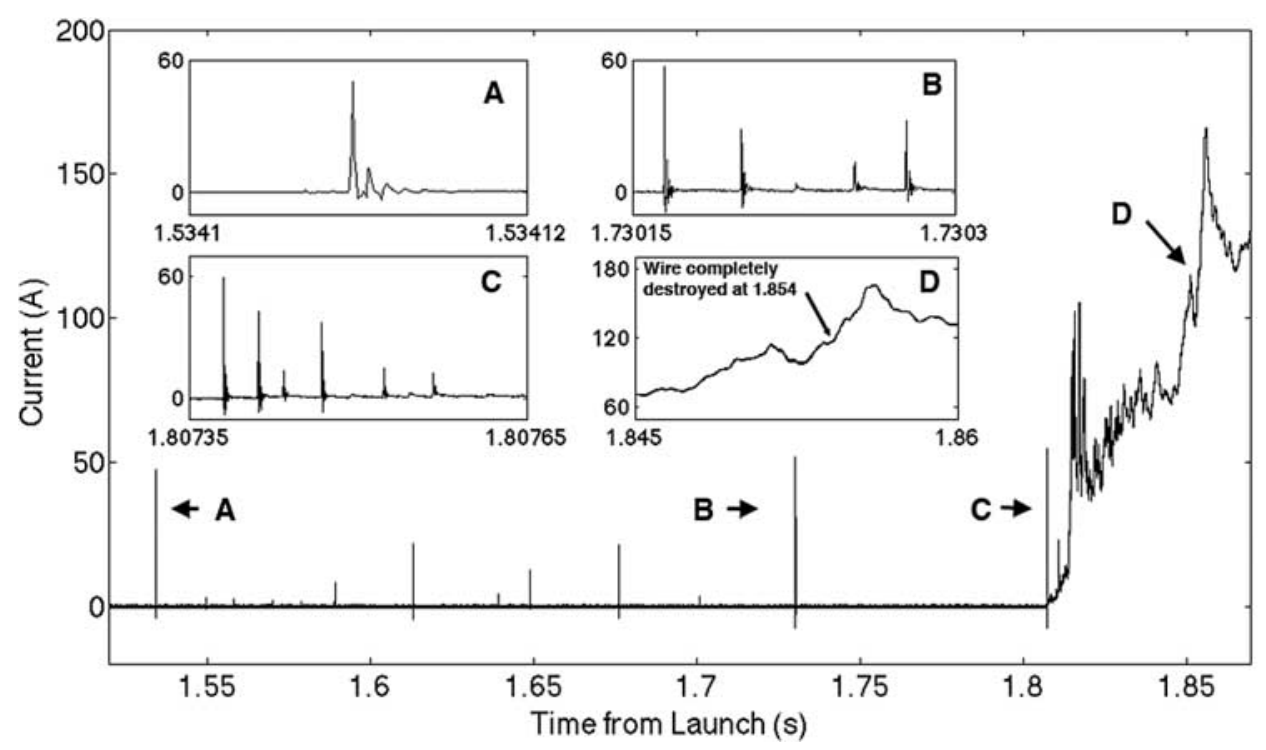

Figure 1. The ICC-path current measurement during the rocket ascent and the beginning of the ICC. The two precursors that produced visible leader channels are labeled A and B. The sustained UPL began at the point labeled C, and the wire destruction occurred at point $\mathrm{D}$. The four inset plots are time-expanded views of these features.

current from the first precursor to just after the wire destruction. Precursors occurred from about $1.53 \mathrm{~s}$ to $1.73 \mathrm{~s}$ every 8 to $30 \mathrm{~ms}$. The two largest precursors are shown on expanded time scales in the inset plots $\mathrm{A}$ and $\mathrm{B}$. The number of pulses in each precursor pulse burst increased with time. The time between individual pulses in a burst was several tens of $\mu \mathrm{s}$. Precursor pulse oscillation periods inside bursts varied between $400 \mathrm{~ns}$ to $800 \mathrm{~ns}$ in no clear systematic way.

[7] Precursors have been attributed to positive-polarity corona streamers (filamentary, low-current breakdown where the electron energy far exceeds that of the neutral particles and ions) emanating from the wire tip, but it has not been known if these develop into transient leader channels (thermalized arcs) that fail to propagate in an electric field that is insufficient to sustain stable propagation [e.g., Lalande et al., 1998]. In our high-speed video data, channels having luminosities equal to the sustained UPL that initiated the flash (discussed in section 3.2) were detected in single frames on camera 1 with precursors A and $\mathrm{B}$ (the largest two), and these are shown in Figure 2 (left). Precursor A corresponded to a vertical channel that was $1.5 \mathrm{~m}$ long at a height of $128 \mathrm{~m}$ AGL; precursor B corresponded to a bent but generally vertical channel $8 \mathrm{~m}$ long at a height of $158 \mathrm{~m}$ AGL. Apparently not every precursor produces a detectable (at least with our system)

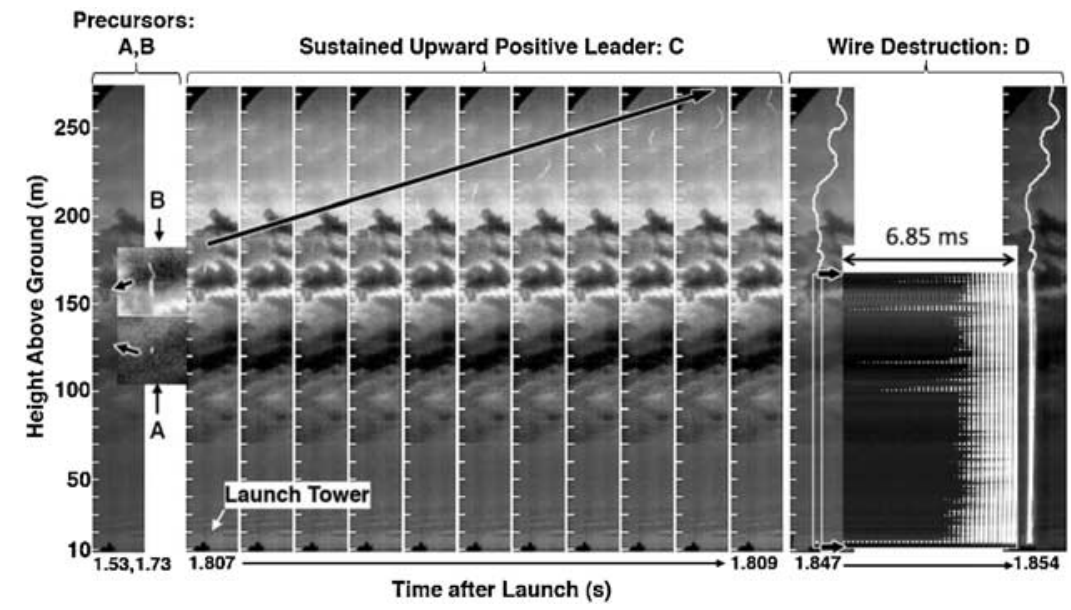

Figure 2. (left) High-speed video data of the luminosity observed for precursors at times $1.53 \mathrm{~s}$ and $1.73 \mathrm{~s}$ (enlarged by a factor of two from the scale on the left) labeled A and B, respectively, in Figure 1, (middle) the sustained UPL, and (right) the destruction of the wire. The times for each $185 \mu \mathrm{s}$ frame are given at the bottom. The black arrows with the precursor images show the height where they occurred. The long black arrow indicates the height progression of the sustained UPL tip. The white rectangle in the frame at time 1.847 identifies the pixel sub-region extracted to produce the $6.85 \mathrm{~ms}$ streak image. 


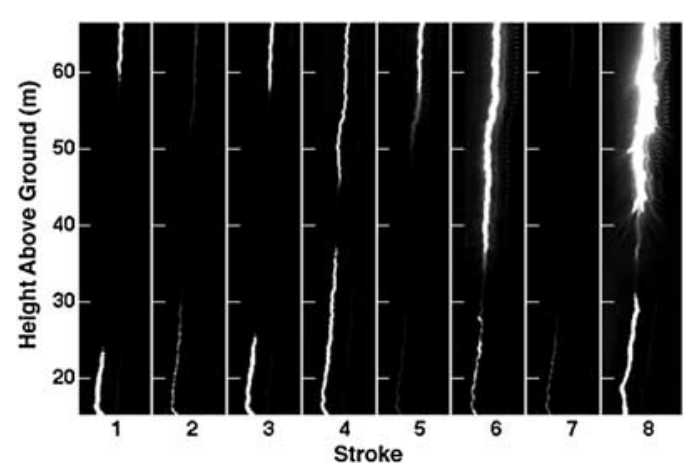

Figure 3. Upward and downward leaders for return strokes one through eight, as observed on camera 2. Each image is the subtraction of the two frames prior to the corresponding return stroke leaving only leader luminosity. The top of the launch tower is just below the images.

aborted leader, although corona streamers likely and arcs possibly occurred that were not sufficiently luminous for detection.

\subsection{Sustained Upward Positive Leader}

[8] A sustained UPL that developed from the wire, starting about $1.81 \mathrm{~s}$ (point $\mathrm{C}$ in Figure 1) after launch when the rocket was at an altitude of about $168 \mathrm{~m} \mathrm{AGL}$, was imaged in 11 consecutive $185 \mu$ s frames (recorded on camera 1) shown in Figure 2 (middle). New channel segments in successive frames were more luminous than the previously established channel, indicating the UPL was likely stepped. Inset $\mathrm{C}$ in Figure 1 gives the current record during the first 2 frames of the UPL on an expanded time scale of $300 \mu \mathrm{s}$, showing it began with a burst of six damped-oscillatory pulses similar to the precursors. However, unlike the precursor pulses, the oscillation period of the six pulses in the burst increased with each pulse, from $400 \mathrm{~ns}$ to $1.2 \mu$ s during a time of $200 \mu \mathrm{s}$. Thereafter, the UPL current measured at ground exhibited unipolar current pulses that decreased in amplitude, making a transition to a steadily increasing continuous current that led to the destruction of the wire about $45 \mathrm{~ms}$ later. The transition from oscillating pulses to unipolar pulses to steady current increase may have been due to increasing channel resistance as the UPL channel grew longer. Based on the location of the leader tip in each succeeding frame, the UPL speed in the vertical direction was constant at $5.6 \times 10^{4} \mathrm{~m} \mathrm{~s}^{-1}$ over the $100 \mathrm{~m}$ field of view above the wire.

\subsection{Destruction of the Triggering Wire}

[9] The wire destruction began $45.4 \mathrm{~ms}$ after the inception of the UPL (at $1.847 \mathrm{~s}$ in Figure 2) when light appeared on the wire at $145 \mathrm{~m}$ AGL. During the next $6.85 \mathrm{~ms}$, more distinct points of light appeared along the wire until it was entirely luminous (and presumably completely destroyed) at a time labeled D (at $1.854 \mathrm{~s}$ ) in Figure 1. Figure 2 (right) shows the frames at the beginning and end of the wire destruction, and in between these is a simulated streak photograph that was created by extracting a sub-region of $424 \times 7$ pixels from each frame that showed the wire destruction and merging them horizontally. There was no clear upward or downward progression or other pattern in the appearance of the spots of light. Current during the wire destruction is shown on an expanded time scale of $15 \mathrm{~ms}$ in inset $\mathrm{D}$ in Figure 1. The changes (decrease) in current during the wire destruction between $1.847 \mathrm{~s}$ and $1.854 \mathrm{~s}$ in Figure 1 may indicate an initial current variation (ICV) [Wang et al., 1999b], although not a pronounced one.

[10] Prior to the wire destruction, $2.7 \mathrm{C}$ of charge were transferred, the average current was $59 \mathrm{~A}$, and the peak current was $115 \mathrm{~A}$. These values are significantly less than those reported by Wang et al. [1999b], Rakov et al. [2003], and Olsen et al. [2006] for triggered lightning with distinct ICVs. However, the same authors reported action integrals about half as large as ours, $192 \mathrm{~A}^{2} \mathrm{~s}$, although a value of $198 \mathrm{~A}^{2} \mathrm{~s}$ was reported for one flash by Rakov et al. [2003]. Our larger action integral is likely due to the fact that our wire destruction occurred at a lower overall current but over a much longer time, $45.4 \mathrm{~ms}$, after the onset of the UPL, an order of magnitude longer than the GM value of $8.6 \mathrm{~ms}$ reported by Wang et al. [1999b] and the range of $1.8 \mathrm{~ms}$ to $2.4 \mathrm{~ms}$ reported by Rakov et al. [2003] for time between the initiation of the UPL and the ICV. As suggested in the work of Olsen et al. [2006], the relatively long and low-level current up to the wire destruction was likely related to the relatively slow and discontinuous nature of the destruction. Further, the small reduction in current (ICV) was apparently related to the slow destruction of the wire. Even though the ICC terminated $330 \mathrm{~ms}$ after the wire destruction, the wire-remains and UPL channel above were luminous for an additional $110 \mathrm{~ms}$, up to the time of the first return stroke.

\subsection{Leaders Preceding Return Strokes}

[11] Camera 1 imaged upward connecting and downward leaders in one $185 \mu$ s frame prior to the first return stroke, and downward leaders in a single $185 \mu$ s frame before return strokes 6 and 8. Camera 2, with a higher frame rate of $20 \mu$ s per frame, imaged upward connecting and downward leaders for strokes 1 through 8 , and these are depicted in Figure 3. Each image in Figure 3 represents the subtraction, or difference in luminosity, of the two $20 \mu$ s frames preceding the first $20 \mu$ s frame containing the return stroke, thus reducing the remnant luminosity from the previous return stroke channel, and emphasizing primarily upward and downward leader luminosity. Two $20 \mu$ s frames of the dart-leader were imaged preceding return stroke 8; true value and negative value images for both frames (not subtracted) are shown in Figure 4 with $100 \mu$ s of current and electric field data, centered on return stroke 8. Leaders preceding return stroke 9 were not observed. The artificial periodic noise to the right of the leaders in Figures 3 and 4 is likely due to internal reflections in the camera.

[12] Regions of channel that saturated the sensor (bright white) distinguish the leader channel (thermalized arc) from the lower levels of luminosity produced in what we will refer to as streamer zones (non-thermalized electrical breakdown primarily composed of filamentary corona streamers) on the sides and in front of the leader channels, particularly for the downward leaders in strokes 6 and 8 . The lengths of the streamer zones preceding strokes $2,3,5,6$, and 7 were $16 \mathrm{~m}, 4 \mathrm{~m}, 10 \mathrm{~m}, 3 \mathrm{~m}$, and $12 \mathrm{~m}$, respectively. Streamer zones were not evident on the positive upward connecting leaders. The leader channels were significantly less luminous for strokes 2 and 7 than the other strokes, possibly because only streamers were imaged, or alternatively, 


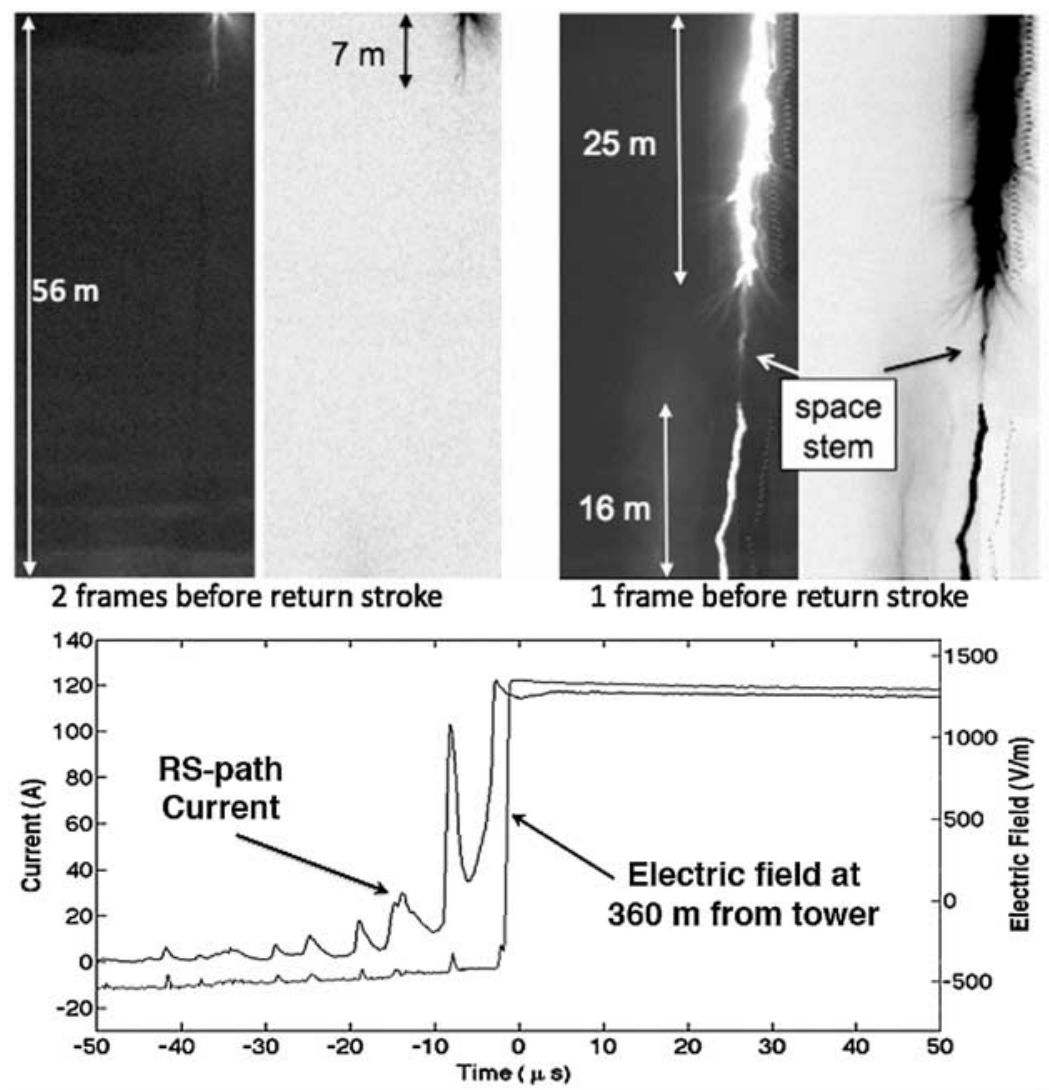

Figure 4. An enhanced and enlarged view of the two frames (and their negatives) recorded on camera 2 (top) before return stroke 8 along with (bottom) $100 \mu$ s of electric field and current centered on return stroke 8 . The current and electric field both saturated before the return stroke.

because less charge was deposited along the leader channel resulting in less current and thus less luminosity [Idone and Orville, 1985]. The locations of the upward and downward leaders in strokes 4 and 6 , for example, indicate that the attachment heights were different for these two return strokes as they likely were for all nine strokes.

[13] The electric field data indicate that dart leaders preceded strokes 1, 2, 3, 4, 7, and 9, and that dart-stepped leaders, characterized by pronounced electric field pulses, preceded strokes 5,6 , and 8 (shown for return stroke 8 in Figure 4). This observation is consistent with the high-speed video data; there are larger, more luminous streamer zones around the downward leaders of strokes 5, 6 and 8 than for the other strokes. Upward connecting leaders were observed preceding strokes 1 through 8 , but correlated current and electric field pulses only preceded strokes 5, 6 and 8, suggesting that the current pulses were caused by induced effects or displacement currents from downward leader steps, while the electric field pulses were radiated from the downward steps. In this view, there is no evidence that the upward connecting leaders were stepped. Alternatively, the upward connecting leader may have been stepped only when, and in response to, corresponding downward leader stepping.

[14] As seen in Figure 4, a $7 \mathrm{~m}$ long streamer zone is visible at the top of the second frame before return stroke 8 . In the next frame, the downward leader extended about $25 \mathrm{~m}$ into the frame. If the leader is just above the image two frames before the return stroke, the leader traveled $25 \mathrm{~m}$ in two frames $(20-40 \mu \mathrm{s})$, and hence its speed was between $1.25 \times 10^{6}-2.5 \times 10^{6} \mathrm{~m} \mathrm{~s}^{-1}$. Dart-stepped leader speeds measured near ground in triggered lighting with the ALPS photodiode array by Wang et al. [1999b] are between $2 \times$ $10^{6} \mathrm{~m} \mathrm{~s}^{-1}$ and $8 \times 10^{6} \mathrm{~m} \mathrm{~s}^{-1}$. Schonland [1956] found speeds of $0.5 \times 10^{6} \mathrm{~m} \mathrm{~s}^{-1}$ to $1.7 \times 10^{6} \mathrm{~m} \mathrm{~s}^{-1}$ for natural dart stepped-leaders. The downward leader observed one frame prior to the return stroke in Figure 4 has several short branches along its path that emanate corona streamers up to $5 \mathrm{~m}$ long. An upward connecting leader that is $16 \mathrm{~m}$ long is also visible. The downward and upward connecting leaders are about $12 \mathrm{~m}$ apart in the frame, and there is a low level of luminosity connecting them (that was not remnant channel luminosity from return stroke 7), apparently indicating that the downward streamer zone has reached the upward connecting leader.

\subsection{Development of a Negative Leader Step in Lightning}

[15] In laboratory sparks, negative leader steps are initiated when a bi-directional streamer forms ahead of the leader tip, with positive streamers extending back toward the leader, and negative streamers extending away from the leader; this process being followed by the bi-directional streamer subsequently thermalizing and becoming a bi-directional conductive arc (called a "space stem" or "space leader") that joins with the leader channel, 
completing the step [e.g., Williams, 2006]. Although this process is well documented on streak photographs for laboratory sparks [e.g., Bazelyan and Raizer, 1998; Gallimberti et al., 2002], it has never been observed for negative steps in lightning, and hence it has been unclear if a similar process is involved in the stepping of lightning leaders. In the frame prior to the eighth return stroke (see Figure 4), a $2 \mathrm{~m}$ segment that is more luminous than the surrounding streamer zone is apparent $4 \mathrm{~m}$ below the downward leader. We believe this is a 'space stem' that helped initiate the next step of the downward stepped leader, and that this image is the first visual documentation showing that step formation in lightning is analogous to step formation in laboratory sparks. This image appears very similar to images recorded via streak photography of a negative leader in a $1.4 \mathrm{~m}$ spark gap [Bazelyan and Raizer, 1998], and of $7 \mathrm{~m}$ point-to-plane negative sparks [Gallimberti et al., 2002]. Further, in the final $185 \mu$ s frame of camera 1 taken before return stroke 8 , a similar space stem of about $4 \mathrm{~m}$ length is evident at a height of $250 \mathrm{~m} \mathrm{AGL}$, imaged prior to the two frames in Figure 4.

[16] Acknowledgments. The research reported here was funded in part by the DARPA (HR0011-08-1-0088) and FAA (99-G-043). Appreciation is due to Mike Stapleton and Julia Jordan, who assisted in experimental setup, maintenance, and data gathering.

\section{References}

Ballarotti, M. G., M. M. F. Saba, and O. Pinto Jr. (2005), High-speed camera observations of negative ground flashes on a millisecond-scale, Geophys. Res. Lett., 32, L23802, doi:10.1029/2005GL023889.

Bazelyan, E. M., and Y. P. Raizer (1998), Spark Discharge, CRC Press, Boca Raton, Fla.

Berger, K., and E. Vogelsanger (1966), Photographische Blitzuntersuchungen der Jahre 1955-1963 auf dem Monte San Salvatore, Bull. Schweiz. Elektrotech Ver., 57, 599-620.

Gallimberti, I., G. Bacchiega, A. Bondiou-Clergerie, and P. Lalande (2002), Fundamental processes in long air gap discharges, C. R. Phys., 3, 13351359.

Idone, V. P., and R. E. Orville (1985), Correlated peak relative light intensity and peak current in triggered lightning subsequent return strokes, J. Geophys. Res., 90, 6159-6164, doi:10.1029/JD090iD04p06159.

Jordan, D. M., V. P. Idone, V. A. Rakov, M. A. Uman, W. H. Beasley, and H. Jurenka (1992), Observed dart leader speed in natural and triggered lightning, J. Geophys. Res., 97, 9951-9957, doi:10.1029/92JA01458.

Lalande, P., A. Bondiou-Clergerie, P. Laroche, A. Eybert-Berard, J.-P. Berlandis, B. Bador, A. Bonamy, M. A. Uman, and V. A. Rakov (1998), Leader properties determined with triggered lightning techniques, J. Geophys. Res., 103, 14,109-14,115, doi:10.1029/97JD02492.
Lu, W., D. Wang, N. Takagi, V. A. Rakov, M. A. Uman, and M. Miki (2008), Characteristics of the optical pulses associated with a downward branched stepped leader,J. Geophys. Res., 113, D21206, doi:10.1029/2008JD010231.

Olsen, R. C., III, D. M. Jordan, V. A. Rakov, M. A. Uman, and N. Grimes (2004), Observed one-dimensional return stroke propagation speeds in the bottom $170 \mathrm{~m}$ of a rocket-triggered lightning channel, Geophys. Res. Lett., 31, L16107, doi:10.1029/2004GL020187.

Olsen, R. C., III, V. A. Rakov, D. M. Jordan, J. Jerauld, M. A. Uman, and K. J. Rambo (2006), Leader/return-stroke-like processes in the initial stage of rocket-triggered lightning, J. Geophys. Res., 111, D13202, doi:10.1029/2005JD006790.

Orville, R. E., and V. P. Idone (1982), Lightning leader characteristics in the Thunderstorm Research International Program (TRIP), J. Geophys. Res., 87, 11,177-11,192, doi:10.1029/JC087iC13p11177.

Qie, X., and X. Kong (2007), Progression features of a stepped leader process with four grounded leader branches, Geophys. Res. Lett., 34 L06809, doi:10.1029/2006GL028771.

Rakov, V. A., D. E. Crawford, V. Kodali, V. P. Idone, M. A. Uman, G. J. Schnetzer, and K. J. Rambo (2003), Cutoff and reestablishment of current in rocket-triggered lightning, J. Geophys. Res., 108(D23), 4747, doi:10.1029/2003JD003694.

Saba, M. M. F., K. L. Cummins, T. A. Warner, E. P. Krider, L. Z. S. Campos, M. G. Ballarotti, O. Pinto Jr., and S. A. Fleenor (2008), Positive leader characteristics from high-speed video observations, Geophys. Res. Lett., 35, L07802, doi:10.1029/2007GL033000.

Schonland, B. F. J. (1956), The Lightning Discharge, Handb. Phys., 22, 576-628.

Wang, D., V. A. Rakov, M. A. Uman, N. Takagi, T. Watanabe, D. E. Crawford, K. J. Rambo, G. H. Schnetzer, R. J. Fisher, and Z.-I. Kawasaki (1999a), Attachment process in rocket-triggered lightning strokes, J. Geophys. Res., 104, 2143-2150, doi:10.1029/1998JD200070.

Wang, D., V. A. Rakov, M. A. Uman, M. I. Fernandez, K. J. Rambo, G. H. Schnetzer, and R. J. Fisher (1999b), Characterization of the initial stage of negative rocket-triggered lightning, J. Geophys. Res., 104, 4213-4222, doi:10.1029/1998JD200087.

Wang, D., N. Takagi, T. Watanabe, V. A. Rakov, and M. A. Uman (1999c), Observed leader and return-stroke propagation characteristics in the bottom $400 \mathrm{~m}$ of a rocket-triggered lightning channel, J. Geophys. Res., 104, 14,369-14,376, doi:10.1029/1999JD900201.

Willett, J. C., D. A. Davis, and P. Laroche (1999), An experimental study of positive leaders initiating rocket-triggered lightning, Atmos. Res., 51, 189-219, doi:10.1016/S0169-8095(99)00008-3.

Williams, E. R. (2006), Problems in lightning physics: The role of polarity asymmetry, Plasma Sources Sci. Technol., 15, S91-S108, doi:10.1088/ 0963-0252/15/2/S12.

Yokoyama, S., K. Miyake, T. Suzuki, and S. Kanao (1990), Winter lightning on Japan Sea coast: Development of measuring system on progressing feature of lightning discharge, IEEE Trans. Power Delivery, 5, 14181425, doi:10.1109/61.57984.

W. H. Beasley, School of Meteorology, University of Oklahoma, Norman, OK 73019-1013, USA.

C. J. Biagi, J. D. Hill, J. Howard, D. M. Jordan, and M. A. Uman, Department of Electrical and Computer Engineering, University of Florida, Gainesville, FL 32611, USA. (biagi@ufl.edu) 